Original Research Paper

\title{
Dynamic Elements at MP3R
}

\author{
${ }^{1}$ Relly Victoria Petrescu, ${ }^{2}$ Raffaella Aversa, ${ }^{3}$ Bilal Akash, ${ }^{2}$ Antonio Apicella and \\ ${ }^{1}$ Florian Ion Tiberiu Petrescu \\ ${ }^{I}$ ARoTMM-IFToMM, Bucharest Polytechnic University, Bucharest, (CE), Romania \\ ${ }^{2}$ Advanced Material Lab, Department of Architecture and Industrial Design, \\ Second University of Naples, 81031 Aversa (CE), Italy \\ ${ }^{3}$ Dean of School of Graduate Studies and Research, American University of Ras Al Khaimah, UAE
}

Article history

Received: 30-10-2017

Revised: 08-11-2017

Accepted: 23-11-2017

Corresponding Author: Florian Ion Tiberiu Petrescu ARoTMM-IFToMM, Bucharest Polytechnic University, Bucharest, (CE), Romania E-mail: scipub02@gmail.com

\begin{abstract}
Mechatronic robotic systems are today widely used worldwide to ease human work, but especially where work is dangerous, in toxic, radioactive, chemical, explosive atmospheres, without air such as underwater or in the cosmos, or in places hard to reach the man. Robots can take the tedious repetitive work under any circumstances and they can perform a difficult operation for a long time, with no meal or rest breaks. Serial mobile mechanical systems are generally the most used mechatronic systems because they have good dynamics, high reliability and lower manufacturing cost with modest technologies. In general, anthropomorphic robotic structures are generally used in serial mechanical systems as they are more versatile, more economical, more reliable, more penetrating, faster and generally have a beautiful and innovative design. Anthropomorphic structures have been used for the first time in the automotive industry to facilitate human work, but also to replace it with repetitive, tiring, or toxic work. For this reason, the first anthropomorphic robots were manipulators and the following were dyeing robots in toxic environments, so that welding anthropomorphic, assemblies, those who checked technological lines and so on would still appear. Almost all operations in the automotive industry were automated based on anthropomorphic robots. For this reason, their study is today as necessary as ever for their continuous improvement. Anthropomorphic robots work at high speeds and therefore their dynamics is an extremely important issue. In this paper, we aim to present an original method of scientific, analytical study of the dynamics of the anthropomorphic mobile mechanical structures. Dynamics is the discipline that studies the real movement of a point, object, or a body, mechanical system ... The dynamic study attempts to capture the real movement of the studied object, as it is in reality. The movement of a body is derailed by the kinematic equations, the movement being generally studied by the kinematics, but when we are interested in the actual movements of a binding object, a dynamic motion study must be introduced. The dynamics besides the kinematics constrain the influence of the masses and forces on the movement of a body, as well as the elastic deformations, the inertial forces, or other external forces capable of influencing the movement of the body, including those caused by the bonds of the body, its object of that mechanism.
\end{abstract}

Keywords: Dynamic, Cinematic of the MP-3R Systems, Geometry, Kinematic Parameters, Dynamics of MP3R

\section{Introduction}

Serial mobile mechanical systems are generally the most used mechatronic systems because they have good dynamics, high reliability and lower manufacturing cost with modest technologies. In 
general, anthropomorphic robotic structures are generally used in serial mechanical systems as they are more versatile, more economical, more reliable, more penetrating, faster and generally have a beautiful and innovative design.

Anthropomorphic structures have been used for the first time in the automotive industry to facilitate human work, but also to replace it with repetitive, tiring, or toxic work. For this reason, the first anthropomorphic robots were manipulators and the following were dyeing robots in toxic environments, so that welding anthropomorphic, assemblies, those who checked technological lines and so on would still appear. Almost all operations in the automotive industry were automated based on anthropomorphic robots. For this reason, their study is today as necessary as ever for their continuous improvement. Anthropomorphic robots work at high speeds and therefore their dynamics is an extremely important issue. In this paper, we aim to present an original method of scientific, analytical study of the dynamics of the anthropomorphic mobile mechanical structures.

Dynamics is the discipline that studies the real movement of a point, object, or body, mechanical system ... The dynamic study attempts to capture the real movement of the studied object, as it is in reality. The movement of a body is derailed by the kinematic equations, the movement being generally studied by the kinematics, but when we are interested in the actual movements of a binding object, a dynamic motion study must be introduced. The dynamics besides the kinematics constrain the influence of the masses and forces on the movement of a body, as well as the elastic deformations, the inertial forces, or other external forces capable of influencing the movement of the body, including those caused by the bonds of the body, its object of that mechanism (Fig. 1).

Antonescu and Petrescu (1985; 1989; Antonescu et al., 1985a-b; 1986-1988; 1994; 1997; 2000a-b; 2001; Aversa et al., 2017a-e; 2016a-o; Berto et al., 2016a-d; Cao et al., 2013; Dong et al., 2013; Comanescu et al., 2010; Franklin, 1930; He et al., 2013; Lee, 2013; Lin et al., 2013; Liu et al., 2013; Mirsayar et al., 2017; Padula and Perdereau, 2013; Perumaal and Jawahar, 2013; Petrescu, 2011; 2015a-b; Petrescu and Petrescu, 1995a-b; 1997a-c; 2000a-b; 2002a-b; 2003; 2005a-e; 2011; 2012a-b; 2013a-b; 2016a-c; Petrescu et al., 2009; 2016; 2017a-1).

\section{Materials and Methods}

In Fig. 1, the weight centers of the MP-3R system were represented. For each element, two elements were considered to be able to perform the calculations separately for the different directions of the parts of each element.

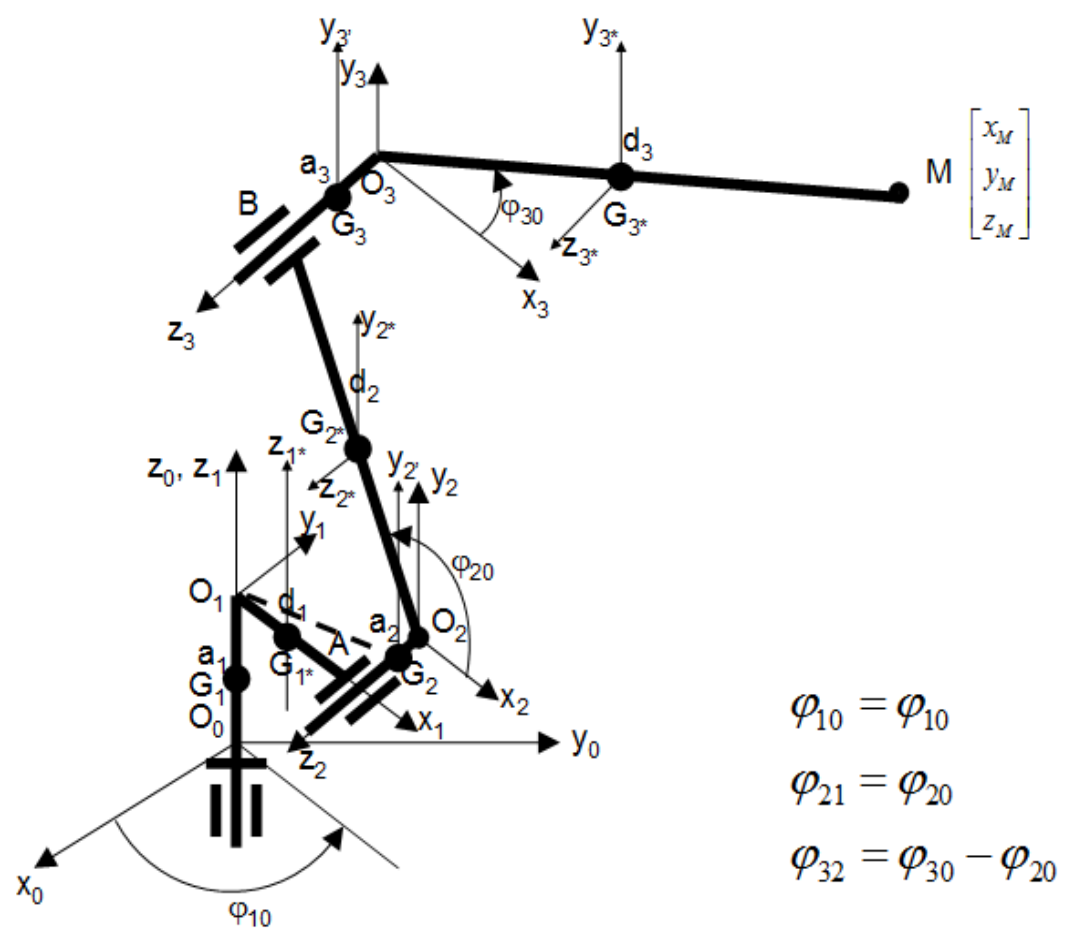

Fig. 1: Geometry, kinematics and dynamics of an MP3R every elements' center of gravity 
Thus element 1 was separated into two parts $O_{0} O_{1}$ with the center of gravity in $G_{1}$ and $O_{1} A$ with the center of gravity in $G_{1 *}$. Element two was divided into two subelements: $\mathrm{AO}_{2}$ with the center of gravity in $\mathrm{G}_{2}$ and $\mathrm{O}_{2} \mathrm{~B}$ with the center of gravity in $\boldsymbol{G}_{2^{*}}$. The last element (MP$3 \mathrm{R}$ 's third element) was also reconsidered and divided into two sub-elements: $\mathrm{BO}_{3}$ with the center of gravity in $G_{3}$ and $O_{3} M$ with the center of gravity in $G_{3 *}$. All the centers of gravity positioned in the middle of the respective elements were considered to be the calculations, the elements being of the bar type (cylindrical or other shapes).

The dynamics of any system requires knowledge of the mechanical kinetic energy of the system. It is the starting point for the number one of determining dynamic calculations and relationships of any mechanical system. The problem with MP-3R systems is that they work spatially, so the kinetic energy of the system includes spatial elements (it can't fit only in a plan).

The Lagrange equation used has the known classical form (1):

$$
\frac{d}{d t}\left(\frac{\partial \varepsilon}{\partial \dot{q}_{k}}\right)-\frac{\partial \varepsilon}{\partial q_{k}}=Q_{k}
$$

With $\mathrm{k}=1,2,3$.

The most normal dynamic determination of a system is made using the Lagrange equations. From system (1) three different equations will be written. For this it is necessary to determine the kinetic energy equation of the considered system beforehand $\left(\varepsilon=\varepsilon\left(q_{k}, \dot{q}_{k}\right)\right)$.

In space, kinetic energy has six components (in the most general case) for each element: Three for linear velocities and three for angular velocities. In the case of linear velocities, rather than writing three kinetic energies (the same mass of the halved element and multiplied separately with the square of each scalar velocity component in the center of the mass), it is simpler to write only one resultant equation, i.e., to multiply half of the mass of the element respectively (in this case, each sub-item will be quoted as an element so that three elements will result in six) with the square of the absolute velocity of the considered element, determined (absolute velocity), in the center of the element. Thus, we will determine the absolute velocities in the mass centers of the elements and the squares of the absolute velocities, then together with the mechanical inertial moments and the squares of the angular velocities of the element determined on three movable axes (movable element) in rectangular shape (virtually a mobile, rectangular, solidarity coordinate system with each element is chosen). In the most general case for each of the six resulting elements, we will have maximum four expressions for the kinetic (mechanical) energy of the system.
Next, the absolute velocities (and their squares) for each of the six system outputs (MP-3R) will be determined.

In the center of gravity $G_{1}$, the absolute speed is null (2):

$v_{G_{1}}=0 \cdot \omega_{1}=0 \theta$

In the center of gravity $G_{1^{*}}$ the absolute speed has the value (3):

$v_{G_{1^{*}}}=\frac{d_{1}}{2} \cdot \omega_{1} \quad v_{G_{1^{*}}}^{2}=\frac{1}{4} \cdot d_{1}^{2} \cdot \omega_{1}^{2}$

In the center of gravity $G_{2}$, the absolute speed gets the expression (4):

$\left\{\begin{array}{l}O_{1} G_{2}=\sqrt{d_{1}^{2}+\left(\frac{a_{2}}{2}\right)^{2}} \\ v_{G_{2}}=O_{1} G_{2} \cdot \omega_{1} \\ v_{G_{2}}^{2}=\left(O_{1} G_{2}\right)^{2} \cdot \omega_{1}^{2}=\left[d_{1}^{2}+\left(\frac{a_{2}}{2}\right)^{2}\right] \cdot \omega_{1}^{2}\end{array}\right.$

In the center of gravity $G_{2 *}$ the square of the absolute velocity takes the form (5):

$$
\left\{\begin{array}{l}
x_{G_{2^{*}}}=d_{1} \cdot \cos \phi_{10}-a_{2} \cdot \sin \phi_{10}+\frac{1}{2} \cdot d_{2} \cdot \cos \phi_{20} \cdot \cos \phi_{10} \\
y_{G_{2^{*}}}=d_{1} \cdot \sin \phi_{10}+a_{2} \cdot \cos \phi_{10}+\frac{1}{2} \cdot d_{2} \cdot \cos \phi_{20} \cdot \sin \phi_{10} \\
z_{G_{2^{*}}}=a_{1}+\frac{1}{2} \cdot d_{2} \cdot \sin \phi_{20} \\
\dot{x}_{G_{2^{*}}}=-d_{1} \cdot \sin \phi_{10} \cdot \omega_{10}-a_{2} \cdot \cos \phi_{10} \cdot \omega_{10}- \\
-\frac{1}{2} \cdot d_{2} \cdot \sin \phi_{20} \cdot \omega_{20} \cdot \cos \phi_{10}-\frac{1}{2} \cdot d_{2} \cdot \cos \phi_{20} \cdot \sin \phi_{10} \cdot \omega_{10} \\
\dot{y}_{G_{2^{*}}}=d_{1} \cdot \cos \phi_{10} \cdot \omega_{10}-a_{2} \cdot \sin \phi_{10} \cdot \omega_{10}- \\
-\frac{1}{2} \cdot d_{2} \cdot \sin \phi_{20} \cdot \omega_{20} \cdot \sin \phi_{10}+\frac{1}{2} \cdot d_{2} \cdot \cos \phi_{20} \cdot \cos \phi_{10} \cdot \omega_{10} \\
\dot{z}_{G_{2^{*}}}=\frac{1}{2} \cdot d_{2} \cdot \cos \phi_{20} \cdot \omega_{20} \\
v_{G_{2^{*}}}^{2}=d_{1}^{2} \cdot \omega_{10}^{2}+a_{2}^{2} \cdot \omega_{10}^{2}+\frac{1}{4} \cdot d_{2}^{2} \cdot \omega_{20}^{2}+\frac{1}{4} \cdot d_{2}^{2} \cdot \omega_{10}^{2} \cdot \cos ^{2} \phi_{20}+ \\
+d_{1} \cdot d_{2} \cdot \omega_{10}^{2} \cdot \cos \phi_{20}+a_{2} \cdot d_{2} \cdot \omega_{10} \cdot \omega_{20} \cdot \sin \phi_{20}
\end{array}\right.
$$

In the center of gravity $G_{3}$, the scalar scoring coordinates take the form (6) and the square of the absolute velocity takes the form (7):

$$
\left\{\begin{array}{l}
x_{G_{3}}=d_{1} \cdot \cos \phi_{10}-\left(a_{2}+\frac{1}{2} a_{3}\right) \cdot \sin \phi_{10}+ \\
+d_{2} \cdot \cos \phi_{10} \cdot \cos \phi_{20} \\
y_{G_{3}}=d_{1} \cdot \sin \phi_{10}+\left(a_{2}+\frac{1}{2} a_{3}\right) \cdot \cos \phi_{10}+ \\
+d_{2} \cdot \sin \phi_{10} \cdot \cos \phi_{20} \\
z_{G_{3}}=a_{1}+d_{2} \cdot \sin \phi_{20}
\end{array}\right.
$$




$$
\left\{\begin{array}{l}
\dot{x}_{G_{3}}=-d_{1} \cdot \sin \phi_{10} \cdot \omega_{10}-\left(a_{2}+\frac{1}{2} a_{3}\right) \cdot \cos \phi_{10} \cdot \omega_{10}-d_{2} \cdot \sin \phi_{10} \cdot \omega_{10} \cdot \cos \phi_{20}-d_{2} \cdot \cos \phi_{10} \cdot \sin \phi_{20} \cdot \omega_{20} \\
\dot{y}_{G_{3}}=d_{1} \cdot \cos \phi_{10} \cdot \omega_{10}-\left(a_{2}+\frac{1}{2} a_{3}\right) \cdot \sin \phi_{10} \cdot \omega_{10}+d_{2} \cdot \cos \phi_{10} \cdot \omega_{10} \cdot \cos \phi_{20}-d_{2} \cdot \sin \phi_{10} \cdot \sin \phi_{20} \cdot \omega_{20} \\
\dot{z}_{G_{3}}=d_{2} \cdot \cos \phi_{20} \cdot \omega_{20} \\
v_{G_{3}}^{2}=\dot{x}_{G_{3}}^{2}+\dot{y}_{G_{3}}^{2}+\dot{z}_{G_{3}}^{2}=d_{1}^{2} \cdot \omega_{10}^{2}+d_{2}^{2} \cdot \omega_{20}^{2} \cdot \cos ^{2} \phi_{20}+ \\
+\left(a_{2}+\frac{1}{2} a_{3}\right)^{2} \cdot \omega_{10}^{2}+d_{2}^{2} \cdot \omega_{10}^{2} \cdot \cos ^{2} \phi_{20}+d_{2}^{2} \cdot \omega_{20}^{2} \cdot \sin ^{2} \phi_{20}+ \\
+2 \cdot d_{1} \cdot d_{2} \cdot \omega_{10}^{2} \cdot \cos \phi_{20}+2 \cdot d_{2} \cdot\left(a_{2}+\frac{1}{2} a_{3}\right) \cdot \sin \phi_{20} \cdot \omega_{10} \cdot \omega_{20} \\
v_{G_{3}}^{2}=\left[d_{1}^{2}+\left(a_{2}+\frac{1}{2} a_{3}\right)^{2}+d_{2}^{2} \cdot \cos ^{2} \phi_{20}+2 \cdot d_{1} \cdot d_{2} \cdot \cos \phi_{20}\right] \cdot \omega_{10}^{2}+ \\
+d_{2}^{2} \cdot \omega_{20}^{2}+2 \cdot d_{2} \cdot\left(a_{2}+\frac{1}{2} a_{3}\right) \cdot \sin \phi_{20} \cdot \omega_{10} \cdot \omega_{20}
\end{array}\right.
$$

In the center of gravity $G_{3}{ }^{*}$ the scalar scoring coordinates take the form (8) and the square of the absolute velocity takes the form (9):

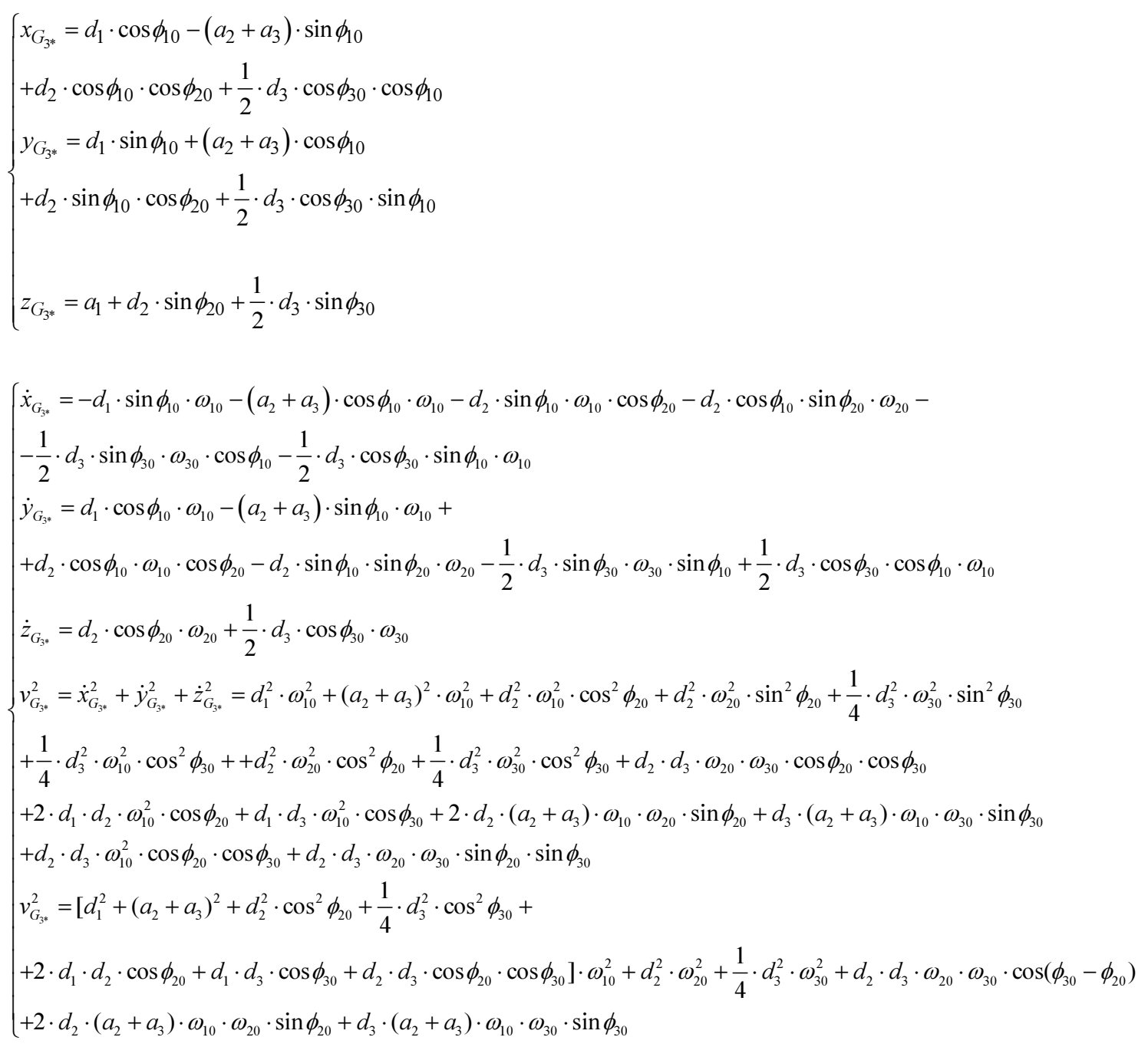


We can now recap the values of all squares of the determined speeds in the six center of gravity of the system (relationship 10):

$$
\left\{\begin{array}{l}
v_{G_{G}}^{2}=0 \\
v_{G_{1^{*}}}^{2}=\frac{1}{4} \cdot d_{1}^{2} \cdot \omega_{1}^{2} \\
v_{G_{2}}^{2}=\left(O_{1} G_{2}\right)^{2} \cdot \omega_{1}^{2}=\left[d_{1}^{2}+\left(\frac{a_{2}}{2}\right)^{2}\right] \cdot \omega_{1}^{2} \\
v_{G_{2^{*}}}^{2}=d_{1}^{2} \cdot \omega_{10}^{2}+a_{2}^{2} \cdot \omega_{10}^{2}+\frac{1}{4} \cdot d_{2}^{2} \cdot \omega_{20}^{2}+\frac{1}{4} \cdot d_{2}^{2} \cdot \omega_{10}^{2} \cdot \cos ^{2} \phi_{20}+d_{1} \cdot d_{2} \cdot \omega_{10}^{2} \cdot \cos \phi_{20}+a_{2} \cdot d_{2} \cdot \omega_{10} \cdot \omega_{20} \cdot \sin \phi_{20} \\
v_{G_{3}}^{2}=\left[d_{1}^{2}+\left(a_{2}+\frac{1}{2} a_{3}\right)^{2}+d_{2}^{2} \cdot \cos ^{2} \phi_{20}+2 \cdot d_{1} \cdot d_{2} \cdot \cos \phi_{20}\right] \cdot \omega_{10}^{2}+d_{2}^{2} \cdot \omega_{20}^{2}+2 \cdot d_{2} \cdot\left(a_{2}+\frac{1}{2} a_{3}\right) \cdot \sin \phi_{20} \cdot \omega_{10} \cdot \omega_{20} \\
v_{G_{3^{*}}}^{2}=\left[d_{1}^{2}+\left(a_{2}+a_{3}\right)^{2}+d_{2}^{2} \cdot \cos ^{2} \phi_{20}+\frac{1}{4} \cdot d_{3}^{2} \cdot \cos ^{2} \phi_{30}+\right. \\
\left.+2 \cdot d_{1} \cdot d_{2} \cdot \cos \phi_{20}+d_{1} \cdot d_{3} \cdot \cos \phi_{30}+d_{2} \cdot d_{3} \cdot \cos \phi_{20} \cdot \cos \phi_{30}\right] \cdot \omega_{10}^{2}+d_{2}^{2} \cdot \omega_{20}^{2}+\frac{1}{4} \cdot d_{3}^{2} \cdot \omega_{30}^{2}+d_{2} \cdot d_{3} \cdot \omega_{20} \cdot \omega_{30} \cdot \cos \left(\phi_{30}-\phi_{20}\right)+ \\
+2 \cdot d_{2} \cdot\left(a_{2}+a_{3}\right) \cdot \omega_{10} \cdot \omega_{20} \cdot \sin \phi_{20}+d_{3} \cdot\left(a_{2}+a_{3}\right) \cdot \omega_{10} \cdot \omega_{30} \cdot \sin \phi_{30}
\end{array}\right.
$$

In Fig. 1, the weight centers of the MP-3R system were represented.

Further, the moments of mass (mechanical) inertia and the kinetic energy relations for each considered kinematic element (as already established there are six elements instead of three) will be determined.

For element $1, O_{0} O_{1}$, determine the moment of mechanical inertia on the main axis, the only one that allows a rotation of the element (relation 11):

$J_{G_{1}}^{z_{1}}=\frac{1}{2} \cdot m_{1} \cdot r_{1}^{2}$

The moment of mechanical inertia (mass) is denoted by $J$. It must be a special moment of geometric inertia, which is generally (correctly) noted with $I$. The moments of mass and geometric inertia always bind to each other through a physical-mathematical relationship. If the geometrical inertial moment is mainly used in the calculations of material resistance and machine tool design, mechanical mechanics, mechanics, mechanisms, robotics, motors, transmissions, (etc ...) the dynamic (physiological) study of the mechanisms and the components of the systems are made mandatory by the inertial masses in motion; the usual masses of the elements (denoted by $m$ ) are used in the translational movement and the inertial masses (denoted by $J$ ) have a determinant role in the rotation movement (of the system elements). There are mechanical (mass) inertial moments projected on a point, on an axis, or on a plane. The convention in mechanics and mechanisms is to generally use the moments of mass inertia projected at a point, usually the point being the center of gravity (mass or symmetry) of that element. For element 1 , we use the center of gravity $G_{1}$ which, for the main z-axis of the element (which is the main axis of rotation) has the same (mechanical) inertial moment at any point of the axis (relation 11). For two rectangular axes $x$ and $y$ the inertial mass moment has the half-value (relation 12), for the most commonly used cases, when we have a cylindrical radial $\mathrm{r}_{1}$ body. Another approximate relationship used for these inertial values when the body is long and very thin (when the radius is negligible in relation to the length) is the relation (13), where $l_{1}$ would be al if the radius $r_{1}$ would be negligible relative to the length $a_{1}$. A more precise (general) relationship for this case would be (14):

$$
\begin{aligned}
& J_{G_{1}}^{x_{1}}=J_{G_{1}}^{y_{1}}=\frac{1}{2} \cdot J_{G_{1}}^{z_{1}}=\frac{1}{4} \cdot m_{1} \cdot r_{1}^{2} \\
& J_{G_{1}}^{x_{1}}=J_{G_{1}}^{y_{1}}=\frac{1}{12} \cdot m_{1} \cdot l_{1}^{2} \\
& J_{G_{1}}^{x_{1}}=J_{G_{1}}^{y_{1}}=\frac{1}{4} \cdot m_{1} \cdot r_{1}^{2}+\frac{1}{12} \cdot m_{1} \cdot a_{1}^{2}
\end{aligned}
$$

Next, we will only use the relation (12) because the systems studied have cylindrical elements with significant diameters (the approximate rays of the cylinders are large enough). If the shape of the element is not cylindrical, it can also be approximated by a cylinder. 
For element 1 , we have no rotation except for the z-axis.

The kinetic energy of element one gets the form (15) (it is considered to be twice the kinetic energy):

$$
\begin{aligned}
& 2 \cdot \varepsilon_{1}=m_{1} \cdot v_{G_{1}}^{2}+J_{G_{1}}^{z_{1}} \cdot \omega_{10}^{2} \\
& =0+\frac{1}{2} \cdot m_{1} \cdot r_{1}^{2} \cdot \omega_{10}^{2}=\frac{1}{2} \cdot m_{1} \cdot r_{1}^{2} \cdot \omega_{10}^{2}
\end{aligned}
$$

On element $1^{*}$, in the center of gravity $G_{1 *}$ the kinetic energy is written (16):

$$
\begin{aligned}
& 2 \cdot \varepsilon_{1^{*}}=m_{1^{*}} \cdot v_{G_{1^{*}}}^{2}+J_{G_{1^{*}}}^{z_{1^{*}}} \cdot \omega_{10}^{2} \\
& =\frac{1}{4} \cdot m_{1^{*}} \cdot d_{1}^{2} \cdot \omega_{10}^{2}+\frac{1}{4} \cdot m_{1^{*}} \cdot r_{1^{*}}^{2} \cdot \omega_{10}^{2} \\
& =\frac{1}{4} \cdot m_{1^{*}} \cdot \omega_{10}^{2} \cdot\left(d_{1}^{2}+r_{1^{*}}^{2}\right)
\end{aligned}
$$

On element 2 in center of gravity $G_{2}$, the kinetic energy takes the form (17):

$$
\begin{aligned}
& 2 \cdot \varepsilon_{2}=m_{2} \cdot v_{G_{2}}^{2}+J_{G_{2}}^{y_{2}^{\prime}} \cdot \omega_{10}^{2}+J_{G_{2}}^{z_{2}} \cdot \omega_{20}^{2}= \\
& =m_{2} \cdot\left(d_{1}^{2}+\frac{1}{4} \cdot a_{2}^{2}\right) \cdot \omega_{10}^{2}+\frac{1}{4} \cdot m_{2} \cdot r_{2}^{2} \cdot \omega_{10}^{2}+\frac{1}{2} \cdot m_{2} \cdot r_{2}^{2} \cdot \omega_{20}^{2}= \\
& =m_{2} \cdot\left(d_{1}^{2}+\frac{1}{4} \cdot a_{2}^{2}+\frac{1}{4} \cdot r_{2}^{2}\right) \cdot \omega_{10}^{2}+\frac{1}{2} \cdot m_{2} \cdot r_{2}^{2} \cdot \omega_{20}^{2}
\end{aligned}
$$

On the element $2 *$ in the center of gravity $G_{2 *}$ the kinetic energy takes the form (18 and 20):

$$
\begin{aligned}
& 2 \cdot \varepsilon_{2^{*}}=m_{2^{*}} \cdot v_{G_{2^{*}}}^{2}+J_{G_{2^{*}}}^{z_{2}^{*}} \cdot \omega_{20}^{2}+J_{G_{2^{*}}}^{y_{2}^{*}} \cdot \omega_{10}^{2}= \\
& =m_{2^{*}} \cdot\left(d_{1}^{2}+a_{2}^{2}+\frac{1}{4} \cdot d_{2}^{2} \cdot \cos ^{2} \phi_{20}+d_{1} \cdot d_{2} \cdot \cos \phi_{20}\right) \cdot \omega_{10}^{2}+ \\
& +\frac{1}{4} \cdot m_{2^{*}} \cdot d_{2}^{2} \cdot \omega_{20}^{2}+m_{2^{*}} \cdot a_{2} \cdot d_{2} \cdot \sin \phi_{20} \cdot \omega_{10} \cdot \omega_{20}+
\end{aligned}
$$

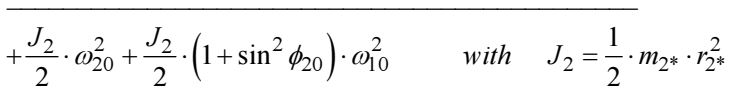

Intermediate relationships (19 and 21) are also used to determine the kinetic energies on the rotating element:

$$
\left\{\begin{array}{l}
J_{G_{2^{*}}}^{z_{2}^{*}} \cdot \omega_{20}^{2}=\frac{J_{2}}{2} \cdot \omega_{20}^{2}=\frac{1}{4} \cdot m_{2^{*}} \cdot r_{2^{*}}^{2} \cdot \omega_{20}^{2} \\
J_{G_{2^{*}}}^{y_{2}^{*}} \cdot \omega_{10}^{2}=\frac{J_{2}}{2} \cdot\left(1+\sin ^{2} \phi_{20}\right) \cdot \omega_{10}^{2}= \\
=\frac{1}{4} \cdot m_{2^{*}} \cdot r_{2^{*}}^{2} \cdot\left(1+\sin ^{2} \phi_{20}\right) \cdot \omega_{10}^{2}
\end{array}\right.
$$

$$
\left\{\begin{array}{l}
2 \cdot \varepsilon_{2^{*}}=m_{2^{*}} \cdot v_{G_{2^{*}}}^{2}+J_{G_{2^{*}}}^{z_{2}^{*}} \cdot \omega_{20}^{2}+J_{G_{2^{*}}}^{y_{2}^{*}} \cdot \omega_{10}^{2}= \\
=\left[d_{1}^{2}+a_{2}^{2}+\frac{1}{4} \cdot d_{2}^{2} \cdot \cos ^{2} \phi_{20}+\right. \\
\left.+d_{1} \cdot d_{2} \cdot \cos \phi_{20}+\frac{1}{4} \cdot r_{2^{*}}^{2} \cdot\left(1+\sin ^{2} \phi_{20}\right)\right] \\
\cdot m_{2^{*}} \cdot \omega_{10}^{2}+\frac{1}{4} \cdot m_{2^{*}} \cdot\left(d_{2}^{2}+r_{2^{*}}^{2}\right) \cdot \omega_{20}^{2}+ \\
+m_{2^{*}} \cdot a_{2} \cdot d_{2} \cdot \sin \phi_{20} \cdot \omega_{10} \cdot \omega_{20}
\end{array}\right.
$$

Relationships (21) explain how to get expressions (19); Fig. 2, where you can see the two different rectangular triangles formed by the axes of point $G_{2 *}$. The moments of mechanical inertia $J_{2 *}$ are known on the $z_{2 *}$ and $x_{b}$ axes, the inertial moment $J_{2}$ on the main axis of the element $2^{*}$ and the inertial moment on the vertical axis $y_{2 *}$ but inclined towards the angle element (the element is located along the axis $G_{2 * y a}$ ):

$$
\left\{\begin{array}{l}
\bar{\omega}_{a}+\bar{\omega}_{b}=\bar{\omega}_{1} \\
\omega_{a}^{2}+\omega_{b}^{2}=\omega_{1}^{2} \\
\omega_{a}=\omega_{1} \cdot \cos \left(\phi_{20}-90\right)=\omega_{1} \cdot \sin \phi_{20} \\
\omega_{b}=\omega_{1} \cdot \cos \left(180-\phi_{20}\right)=\omega_{1} \cdot \sin \left(\phi_{20}-90\right) \\
J_{G_{2^{*}}}^{y_{2}^{*}} \cdot \omega_{1}^{2}=J_{2} \cdot \omega_{a}^{2}+\frac{J_{2}}{2} \cdot \omega_{b}^{2}=\frac{J_{2}}{2} \cdot \omega_{a}^{2}+\frac{J_{2}}{2} \cdot\left(\omega_{a}^{2}+\omega_{b}^{2}\right) \\
=\frac{J_{2}}{2} \cdot \omega_{a}^{2}+\frac{J_{2}}{2} \cdot \omega_{1}^{2}=\frac{J_{2}}{2} \cdot\left(\omega_{a}^{2}+\omega_{1}^{2}\right)=\frac{J_{2}}{2} \cdot\left(\omega_{1}^{2} \cdot \sin ^{2} \phi_{20}+\omega_{1}^{2}\right) \\
=\frac{J_{2}}{2} \cdot \omega_{1}^{2} \cdot\left(1+\sin ^{2} \phi_{20}\right) \Rightarrow J_{G_{2^{*}}}^{y_{2}^{*}}=\frac{J_{2}}{2} \cdot\left(1+\sin ^{2} \phi_{20}\right)
\end{array}\right.
$$

On element 3 , in the center of gravity $G_{3}$, the kinetic energy takes shape (22) and the final expression (26):

$$
2 \cdot \varepsilon_{3}=m_{3} \cdot v_{G_{3}}^{2}+J_{G_{3}}^{y_{3}^{\prime}} \cdot \omega_{10}^{2}+J_{G_{3}}^{z_{3}} \cdot \omega_{30}^{2}
$$

where, the double of kinetic energy due to translation has the expression (23):

$$
\begin{aligned}
& 2 \cdot \varepsilon_{3 t}=m_{3} \cdot v_{G_{3}}^{2} \\
& =m_{3} \cdot\left[d_{1}^{2}+\left(a_{2}+\frac{1}{2} \cdot a_{3}\right)^{2}+d_{2}^{2} \cdot \cos ^{2} \phi_{20}+2 \cdot d_{1} \cdot d_{2} \cdot \cos \phi_{20}\right] \cdot \omega_{10}^{2} \\
& +m_{3} \cdot d_{2}^{2} \cdot \omega_{20}^{2}+2 \cdot m_{3} \cdot d_{2} \cdot\left(a_{2}+\frac{1}{2} \cdot a_{3}\right) \cdot \sin \phi_{20} \cdot \omega_{10} \cdot \omega_{20}
\end{aligned}
$$

The duplication of the kinetic energies due to the rotation of the element on the two axes is determined by the relations (24 and 25):

$2 \cdot \varepsilon_{3 r y 3^{\prime}}=J_{G_{3}}^{y_{3}^{\prime}} \cdot \omega_{10}^{2}=\frac{1}{4} \cdot m_{3} \cdot r_{3}^{2} \cdot \omega_{10}^{2}$ 


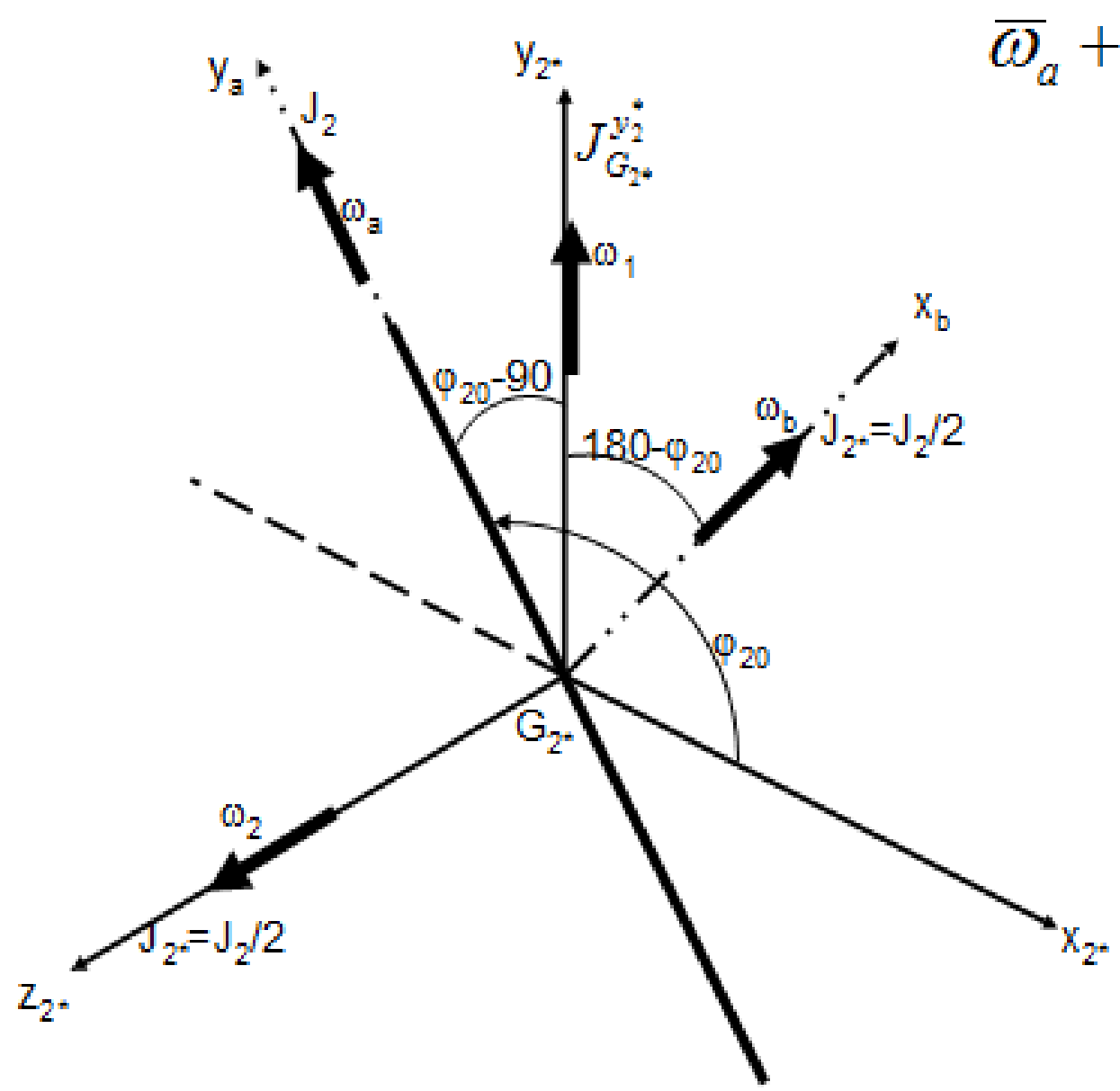

Fig. 2: Geometry and kinematic at $G_{2}{ }^{*}$ Inertial moments

$2 \cdot \varepsilon_{3 r z 3}=J_{G_{3}}^{z_{3}} \cdot \omega_{30}^{2}=\frac{1}{2} \cdot m_{3} \cdot r_{3}^{2} \cdot \omega_{30}^{2}$

$2 \cdot \varepsilon_{3}=$

$=\left[d_{1}^{2}+\left(a_{2}+\frac{1}{2} \cdot a_{3}\right)^{2}+d_{2}^{2} \cdot \cos ^{2} \varphi_{20}+2 \cdot d_{1} \cdot d_{2} \cdot \cos \varphi_{20}+\frac{1}{4} \cdot r_{3}^{2}\right]$.

$\cdot m_{3} \cdot \omega_{10}^{2}+m_{3} \cdot d_{2}^{2} \cdot \omega_{20}^{2}+\frac{1}{2} \cdot m_{3} \cdot r_{3}^{2} \cdot \omega_{30}^{2}+$

$+2 \cdot m_{3} \cdot d_{2} \cdot\left(a_{2}+\frac{1}{2} \cdot a_{3}\right) \cdot \sin \varphi_{20} \cdot \omega_{10} \cdot \omega_{20}$

On element $3^{*}$, in the center of gravity $G_{3^{*}}$, the kinetic energy takes shape (27) and the final expression (31):

$2 \cdot \varepsilon_{3^{*}}=m_{3^{*}} \cdot v_{G_{3}}^{2}+J_{G_{3^{*}}}^{z_{3}^{*}} \cdot \omega_{30}^{2}+J_{G_{3^{*}}}^{y_{3}^{*}} \cdot \omega_{10}^{2}$

where, double of the kinetic energy due to translation has the expression (28):

$$
\left\{\begin{array}{l}
2 \cdot \varepsilon_{3^{*} t}=m_{3^{*}} \cdot v_{G_{3}}^{2} \\
=m_{3^{*}} \cdot\left[d_{1}^{2}+\left(a_{2}+a_{3}\right)^{2}\right. \\
+d_{2}^{2} \cdot \cos ^{2} \phi_{20}+\frac{1}{4} \cdot d_{3}^{2} \cdot \cos ^{2} \phi_{30} \\
+2 \cdot d_{1} \cdot d_{2} \cdot \cos \phi_{20}+d_{1} \cdot d_{3} \cdot \cos \phi_{30} \\
\left.+d_{2} \cdot d_{3} \cdot \cos \phi_{20} \cdot \cos \phi_{30}\right] \cdot \omega_{10}^{2} \\
+m_{3^{*}} \cdot d_{2}^{2} \cdot \omega_{20}^{2}+\frac{1}{4} \cdot m_{3^{*}} \cdot d_{3}^{2} \cdot \omega_{30}^{2} \\
+m_{3^{*}} \cdot d_{2} \cdot d_{3} \cdot \omega_{20} \cdot \omega_{30} \cdot \cos \left(\phi_{30}-\phi_{20}\right) \\
+2 \cdot m_{3^{*}} \cdot d_{2} \cdot\left(a_{2}+a_{3}\right) \cdot \omega_{10} \cdot \omega_{20} \cdot \sin \phi_{20} \\
+m_{3^{*}} \cdot d_{3} \cdot\left(a_{2}+a_{3}\right) \cdot \omega_{10} \cdot \omega_{30} \cdot \sin \phi_{30}
\end{array}\right.
$$

The double of the kinetic energies due to the rotation of the element on the two axes is determined with the relations (29 and 30):

$$
2 \cdot \varepsilon_{3^{*} r z 3^{*}}=J_{G_{3^{*}}}^{z_{3}^{*}} \cdot \omega_{30}^{2}=\frac{J_{3}}{2} \cdot \omega_{30}^{2}=\frac{1}{4} \cdot m_{3^{*}} \cdot r_{3^{*}}^{2} \cdot \omega_{30}^{2}
$$




$$
\begin{aligned}
& 2 \cdot \varepsilon_{3^{*} r y 3^{*}}=J_{G_{3^{*}}}^{y_{3}^{*}} \cdot \omega_{10}^{2}=\frac{J_{3}}{2} \cdot\left(1+\sin ^{2} \phi_{30}\right) \cdot \omega_{10}^{2}= \\
& =\frac{1}{4} \cdot m_{3^{*}} \cdot r_{3^{*}}^{2} \cdot\left(1+\sin ^{2} \phi_{30}\right) \cdot \omega_{10}^{2}
\end{aligned}
$$

$$
\left\{\begin{array}{l}
2 \cdot \varepsilon_{3^{*}}=m_{3^{*}} \cdot\left[d_{1}^{2}+\left(a_{2}+a_{3}\right)^{2}+\right. \\
+d_{2}^{2} \cdot \cos ^{2} \phi_{20}+\frac{1}{4} \cdot d_{3}^{2} \cdot \cos ^{2} \phi_{30}+ \\
+2 \cdot d_{1} \cdot d_{2} \cdot \cos \phi_{20}+d_{1} \cdot d_{3} \cdot \cos \phi_{30}+ \\
+d_{2} \cdot d_{3} \cdot \cos \phi_{20} \cdot \cos \phi_{30}+ \\
\left.+\frac{1}{4} \cdot r_{3^{*}}^{2} \cdot\left(1+\sin ^{2} \phi_{30}\right)\right] \cdot \omega_{10}^{2}+ \\
+m_{3^{*}} \cdot d_{2}^{2} \cdot \omega_{20}^{2}+\frac{1}{4} \cdot m_{3^{*}} \cdot\left(d_{3}^{2}+r_{3^{*}}^{2}\right) \cdot \omega_{30}^{2}+ \\
+m_{3^{*}} \cdot d_{2} \cdot d_{3} \cdot \cos \left(\phi_{30}-\phi_{20}\right) \cdot \omega_{20} \cdot \omega_{30}+ \\
+2 \cdot m_{3^{*}} \cdot d_{2} \cdot\left(a_{2}+a_{3}\right) \cdot \sin \phi_{20} \cdot \omega_{10} \cdot \omega_{20}+ \\
+m_{3^{*}} \cdot d_{3} \cdot\left(a_{2}+a_{3}\right) \cdot \sin \phi_{30} \cdot \omega_{10} \cdot \omega_{30}
\end{array}\right.
$$

\section{Results}

The moments of the drive motors (variation of required moments of the three actuators) will be determined.

The kinetic energy of the entire system is written first, comprising the three elements each dissected in two (32). The kinetic energy relationship of the entire system (32) is very long. Lagrange (1) Lagrange (course 07) is used to obtain practically three expressions corresponding to the three actuators, more precisely corresponding to the moments of the three actuators:

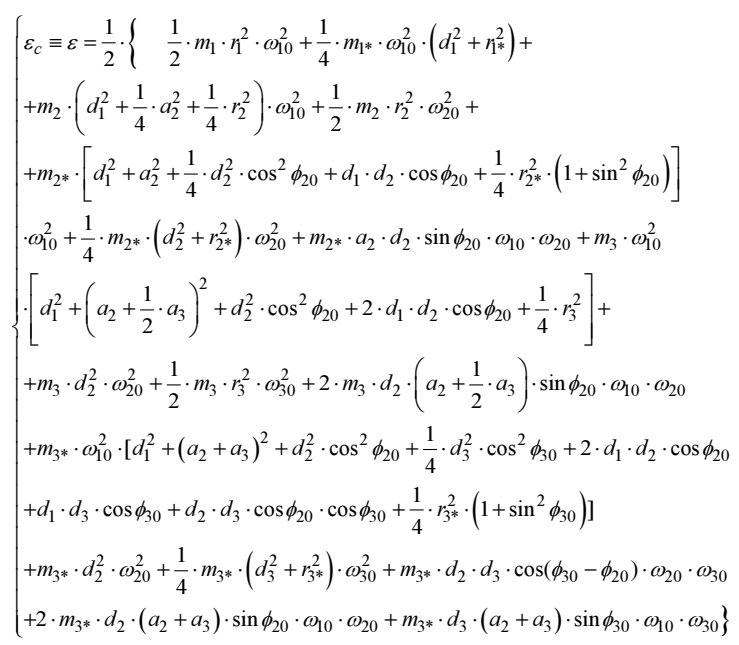

Lagrange equations of the second case have the known classical form (1):

$$
\frac{d}{d t}\left(\frac{\partial \varepsilon}{\partial \dot{q}_{k}}\right)-\frac{\partial \varepsilon}{\partial q_{k}}=Q_{k}
$$

The expression (32) of the kinetic energy of the whole system is used. The independent parameters (the generalized coordinates) are written as (33). $Q_{k}$ represents the generalized forces (in us are even motor moments of actuators):

$\left\{\begin{array}{l}q_{1} \equiv \phi_{10} ; \quad q_{2} \equiv \phi_{20} ; \quad q_{3} \equiv \phi_{30} ; \\ \dot{q}_{1} \equiv \dot{\phi}_{10}=\omega_{10} ; \quad \dot{q}_{2} \equiv \dot{\phi}_{20}=\omega_{20} ; \quad \dot{q}_{3} \equiv \dot{\phi}_{30}=\omega_{30}\end{array}\right.$

The first derivative (relation 34) is the partial derivative of the total kinetic energy (of the whole system) to the independent parameter $\omega_{10}$ (i.e., the partial kinetic energy of the system at the angular velocity of the first actuator is derived):

$$
\left\{\begin{array}{l}
\frac{\partial \varepsilon}{\partial \omega_{10}}=\frac{1}{2} \cdot m_{1} \cdot r_{1}^{2} \cdot \omega_{10}+\frac{1}{4} \cdot m_{1^{*}} \cdot\left(d_{1}^{2}+r_{1^{*}}^{2}\right) \cdot \omega_{10} \\
+m_{2} \cdot\left(d_{1}^{2}+\frac{1}{4} \cdot a_{2}^{2}+\frac{1}{4} \cdot r_{2}^{2}\right) \cdot \omega_{10}+m_{2^{*}} \cdot\left(d_{1}^{2}+a_{2}^{2}+\frac{1}{4} \cdot r_{2^{*}}^{2}\right) \cdot \omega_{10} \\
+m_{2^{*}} \cdot \omega_{10} \cdot\left(\frac{1}{4} \cdot d_{2}^{2} \cdot \cos ^{2} \phi_{20}+d_{1} \cdot d_{2} \cdot \cos \phi_{20}+\frac{1}{4} \cdot r_{2^{*}}^{2} \cdot \sin ^{2} \phi_{20}\right) \\
+\frac{1}{2} \cdot m_{2^{*}} \cdot a_{2} \cdot d_{2} \cdot \omega_{20} \cdot \sin \phi_{20}+m_{3} \cdot \omega_{10} \cdot\left[d_{1}^{2}+\left(a_{2}+\frac{1}{2} \cdot a_{3}\right)^{2}+\frac{1}{4} \cdot r_{3}^{2}\right] \\
+m_{3} \cdot \omega_{10} \cdot\left(d_{2}^{2} \cdot \cos ^{2} \phi_{20}+2 \cdot d_{1} \cdot d_{2} \cdot \cos \phi_{20}\right) \\
+m_{3} \cdot \omega_{20} \cdot d_{2} \cdot\left(a_{2}+\frac{1}{2} \cdot a_{3}\right) \cdot \sin \phi_{20}+m_{3^{*}} \cdot \omega_{10} \cdot\left[d_{1}^{2}+\left(a_{2}+a_{3}\right)^{2}+\frac{1}{4} \cdot r_{3^{*}}^{2}\right. \\
+m_{3^{*}} \cdot \omega_{10} \cdot\left(d_{2}^{2} \cdot \cos ^{2} \phi_{20}+\frac{1}{4} \cdot d_{3}^{2} \cdot \cos \phi_{30}^{2}+2 \cdot d_{1} \cdot d_{2} \cdot \cos \phi_{20}\right. \\
\left.+d_{1} \cdot d_{3} \cdot \cos \phi_{30}+d_{2} \cdot d_{3} \cdot \cos \phi_{20} \cdot \cos \phi_{30}+\frac{1}{4} \cdot r_{3^{*}}^{2} \cdot \sin ^{2} \phi_{30}\right) \\
+m_{3^{*}} \cdot \omega_{20} \cdot d_{2} \cdot\left(a_{2}+a_{3}\right) \cdot \sin \phi_{20}+\frac{1}{2} \cdot m_{3^{*}} \cdot \omega_{30} \cdot d_{3} \cdot\left(a_{2}+a_{3}\right) \cdot \sin \phi_{30}
\end{array}\right.
$$

The expression (34) obtained derives absolutely with time and the relation (35) is obtained. Constant angular velocities have been considered over time:

$$
\left\{\begin{array}{l}
\frac{d}{d t}\left(\frac{\partial \varepsilon}{\partial \omega_{10}}\right)=m_{2 *} \cdot \omega_{10} \cdot\left(-\frac{1}{2} \cdot d_{2}^{2} \cdot \cos \phi_{20} \cdot \sin \phi_{20} \cdot \omega_{20}-d_{1} \cdot d_{2} \cdot \sin \phi_{20} \cdot \omega_{20}\right. \\
\left.+\frac{1}{2} \cdot r_{2^{*}}^{2} \cdot \sin \phi_{20} \cdot \cos \phi_{20} \cdot \omega_{20}\right)+\frac{1}{2} \cdot m_{2 *} \cdot a_{2} \cdot d_{2} \cdot \omega_{20} \cdot \cos \phi_{20} \cdot \omega_{20} \\
+m_{3} \cdot \omega_{10} \cdot\left(-2 \cdot d_{2}^{2} \cdot \cos \phi_{20} \cdot \sin \phi_{20} \cdot \omega_{20}-2 \cdot d_{1} \cdot d_{2} \cdot \sin \phi_{20} \cdot \omega_{20}\right) \\
+m_{3} \cdot \omega_{20} \cdot d_{2} \cdot\left(a_{2}+\frac{1}{2} \cdot a_{3}\right) \cdot \cos \phi_{20} \cdot \omega_{20}+m_{3^{*}} \cdot \omega_{10} \\
\cdot\left(-2 \cdot d_{2}^{2} \cdot \cos \phi_{20} \cdot \sin \phi_{20} \cdot \omega_{20}-\frac{1}{2} \cdot d_{3}^{2} \cdot \cos \phi_{30} \cdot \sin \phi_{30} \cdot \omega_{30}-\right. \\
-2 \cdot d_{1} \cdot d_{2} \cdot \sin \phi_{20} \cdot \omega_{20}-d_{1} \cdot d_{3} \cdot \sin \phi_{30} \cdot \omega_{30}-d_{2} \cdot d_{3} \cdot \sin \phi_{20} \cdot \omega_{20} \cdot \cos \phi_{30} \\
\left.-d_{2} \cdot d_{3} \cdot \cos \phi_{20} \cdot \sin \phi_{30} \cdot \omega_{30}+\frac{1}{2} \cdot r_{3 *}^{2} \cdot \sin \phi_{30} \cdot \cos \phi_{30} \cdot \omega_{30}\right) \\
+m_{3^{*}} \cdot \omega_{20} \cdot d_{2} \cdot\left(a_{2}+a_{3}\right) \cdot \cos \phi_{20} \cdot \omega_{20}+\frac{1}{2} \cdot m_{3 *} \cdot \omega_{30} \cdot d_{3} \cdot\left(c_{2}+a_{3}\right) \cdot \cos \phi_{30} \cdot \omega_{30}
\end{array}\right.
$$


There follows the partial derivative of the kinetic energy of the entire system with the independent parameter (36):

$$
\frac{\partial \varepsilon}{\partial \phi_{10}}=0
$$

The first Lagrange equation (of the three) can now be written as (37):

$$
\frac{d}{d t}\left(\frac{\partial \varepsilon}{\partial \omega_{10}}\right)-\frac{\partial \varepsilon}{\partial \phi_{10}}=M_{10}
$$

By replacing the derivatives derived above in Equation (37), it takes shape (38). The expression (38) represents the required variation of the motor torque of the first actuator:

$$
\left\{\begin{array}{l}
M_{10}=\frac{d}{d t}\left(\frac{\partial \varepsilon}{\partial \omega_{10}}\right)=m_{2^{*}} \cdot \omega_{10} \\
\cdot\left(-\frac{1}{2} \cdot d_{2}^{2} \cdot \cos \phi_{20} \cdot \sin \phi_{20} \cdot \omega_{20}-d_{1} \cdot d_{2} \cdot \sin \phi_{20} \cdot \omega_{20}\right. \\
\left.+\frac{1}{2} \cdot r_{2^{*}}^{2} \cdot \sin \phi_{20} \cdot \cos \phi_{20} \cdot \omega_{20}\right)+\frac{1}{2} \cdot m_{2^{*}} \cdot a_{2} \cdot d_{2} \cdot \omega_{20} \cdot \cos \phi_{20} \cdot \omega_{20} \\
+m_{3} \cdot \omega_{10} \cdot\left(-2 \cdot d_{2}^{2} \cdot \cos \phi_{20} \cdot \sin \phi_{20} \cdot \omega_{20}-2 \cdot d_{1} \cdot d_{2} \cdot \sin \phi_{20} \cdot \omega_{20}\right) \\
+m_{3} \cdot \omega_{20} \cdot d_{2} \cdot\left(a_{2}+\frac{1}{2} \cdot a_{3}\right) \cdot \cos \phi_{20} \cdot \omega_{20}+m_{3^{*}} \cdot \omega_{10} \\
\cdot\left(-2 \cdot d_{2}^{2} \cdot \cos \phi_{20} \cdot \sin \phi_{20} \cdot \omega_{20}-\frac{1}{2} \cdot d_{3}^{2} \cdot \cos \phi_{30} \cdot \sin \phi_{30} \cdot \omega_{30}\right. \\
-2 \cdot d_{1} \cdot d_{2} \cdot \sin \phi_{20} \cdot \omega_{20}-d_{1} \cdot d_{3} \cdot \sin \phi_{30} \cdot \omega_{30} \\
-d_{2} \cdot d_{3} \cdot \sin \phi_{20} \cdot \omega_{20} \cdot \cos \phi_{30} \\
\left.-d_{2} \cdot d_{3} \cdot \cos \phi_{20} \cdot \sin \phi_{30} \cdot \omega_{30}+\frac{1}{2} \cdot r_{3^{*}}^{2} \cdot \sin \phi_{30} \cdot \cos \phi_{30} \cdot \omega_{30}\right) \\
+m_{3^{*}} \cdot \omega_{20} \cdot d_{2} \cdot\left(a_{2}+a_{3}\right) \cdot \cos \phi_{20} \cdot \omega_{20} \\
+\frac{1}{2} \cdot m_{3^{*}} \cdot \omega_{30} \cdot d_{3} \cdot\left(a_{2}+a_{3}\right) \cdot \cos \phi_{30} \cdot \omega_{30}
\end{array}\right.
$$

Next we repeat the previous procedure for the second element, partly deriving the total kinetic energy of the system in relation to the generalized coordinate (representing the angular velocity of the second actuator). The relationship is thus obtained (39):

$$
\left\{\begin{array}{l}
\frac{\partial \varepsilon}{\partial \omega_{20}}=\frac{1}{2} \cdot m_{2} \cdot r_{2}^{2} \cdot \omega_{20}+\frac{1}{4} \cdot m_{2^{*}} \cdot\left(d_{2}^{2}+r_{2^{*}}^{2}\right) \cdot \omega_{20} \\
+\frac{1}{2} \cdot m_{2^{*}} \cdot a_{2} \cdot d_{2} \cdot \sin \phi_{20} \cdot \omega_{10}+m_{3} \cdot d_{2}^{2} \cdot \omega_{20} \\
+m_{3} \cdot d_{2} \cdot\left(a_{2}+\frac{1}{2} \cdot a_{3}\right) \cdot \sin \phi_{20} \cdot \omega_{10}+m_{3^{*}} \cdot d_{2}^{2} \cdot \omega_{20} \\
+\frac{1}{2} \cdot m_{3^{*}} \cdot d_{2} \cdot d_{3} \cdot \cos \left(\phi_{30}-\phi_{20}\right) \cdot \omega_{30} \\
+m_{3^{*}} \cdot d_{2} \cdot\left(a_{2}+a_{3}\right) \cdot \sin \phi_{20} \cdot \omega_{10}
\end{array}\right.
$$

The resulting relationship (39) is derived the second time, this time absolute, depending on time and the expression (40) is obtained. It is considered during this absolute derivation that the angular speeds of the actuators do not vary over time (they are approximately constant):

$$
\left\{\begin{array}{l}
\frac{d}{d t}\left(\frac{\partial \varepsilon}{\partial \omega_{20}}\right)=\frac{1}{2} \cdot m_{2 *} \cdot a_{2} \cdot d_{2} \cdot \cos \phi_{20} \cdot \omega_{20} \cdot \omega_{10} \\
+m_{3} \cdot d_{2} \cdot\left(a_{2}+\frac{1}{2} \cdot a_{3}\right) \cdot \cos \phi_{20} \cdot \omega_{20} \cdot \omega_{10} \\
-\frac{1}{2} \cdot m_{3^{*}} \cdot d_{2} \cdot d_{3} \cdot \sin \left(\phi_{30}-\phi_{20}\right) \cdot\left(\omega_{30}-\omega_{20}\right) \cdot \omega_{30} \\
+m_{3^{*}} \cdot d_{2} \cdot\left(a_{2}+a_{3}\right) \cdot \cos \phi_{20} \cdot \omega_{20} \cdot \omega_{10}
\end{array}\right.
$$

There follows a partial derivative of the kinetic energy of the system according to the angular displacement of the second actuator (41):

$$
\left\{\begin{array}{l}
\frac{\partial \varepsilon}{\partial \phi_{20}}=-\frac{1}{4} \cdot m_{2^{*}} \cdot d_{2}^{2} \cdot \cos \phi_{20} \cdot \sin \phi_{20} \cdot \omega_{10}^{2} \\
-\frac{1}{2} \cdot m_{2^{*}} \cdot d_{1} \cdot d_{2} \cdot \sin \phi_{20} \cdot \omega_{10}^{2} \\
+\frac{1}{4} \cdot m_{2^{*}} \cdot r_{2^{*}}^{2} \cdot \sin \phi_{20} \cdot \cos \phi_{20} \cdot \omega_{10}^{2} \\
+\frac{1}{2} \cdot m_{2^{*}} \cdot a_{2} \cdot d_{2} \cdot \cos \phi_{20} \cdot \omega_{10} \cdot \omega_{20} \\
-m_{3} \cdot d_{2}^{2} \cdot \cos \phi_{20} \cdot \sin \phi_{20} \cdot \omega_{10}^{2} \\
-m_{3} \cdot d_{1} \cdot d_{2} \cdot \sin \phi_{20} \cdot \omega_{10}^{2} \\
+m_{3} \cdot d_{2} \cdot\left(a_{2}+\frac{1}{2} \cdot a_{3}\right) \cdot \cos \phi_{20} \cdot \omega_{20} \cdot \omega_{10} \\
-m_{3^{*}} \cdot d_{2}^{2} \cdot \cos \phi_{20} \cdot \sin \phi_{20} \cdot \omega_{10}^{2} \\
-m_{3^{*}} \cdot d_{1} \cdot d_{2} \cdot \sin \phi_{20} \cdot \omega_{10}^{2} \\
-\frac{1}{2} \cdot m_{3^{*}} \cdot d_{2} \cdot d_{3} \cdot \sin \phi_{20} \cdot \cos \phi_{30} \cdot \omega_{10}^{2} \\
+\frac{1}{2} \cdot m_{3^{*}} \cdot d_{2} \cdot d_{3} \cdot \sin \left(\phi_{30}-\phi_{20}\right) \cdot \omega_{20} \cdot \omega_{30} \\
+m_{3^{*}} \cdot d_{2} \cdot\left(a_{2}+a_{3}\right) \cdot \cos \phi_{20} \cdot \omega_{10} \cdot \omega_{20}
\end{array}\right.
$$

Using the relations (40) and (41) introduced in the Lagrange equation (42), the expression of the alternating motor moment of the second actuator is obtained:

$\frac{d}{d t}\left(\frac{\partial \varepsilon}{\partial \omega_{20}}\right)-\frac{\partial \varepsilon}{\partial \phi_{20}}=M_{20}$ 


$$
\left\{\begin{array}{l}
M_{20}=-\frac{1}{2} \cdot m_{3^{*}} \cdot d_{2} \cdot d_{3} \cdot \sin \left(\phi_{30}-\phi_{20}\right) \cdot \omega_{30}^{2} \\
+\left(m_{3}+m_{3^{*}}+\frac{1}{4} \cdot m_{2^{*}}\right) \cdot d_{2}^{2} \cdot \cos \phi_{20} \cdot \sin \phi_{20} \cdot \omega_{10}^{2} \\
-\frac{1}{4} \cdot m_{2^{*}} \cdot r_{2^{*}}^{2} \cdot \cos \phi_{20} \cdot \sin \phi_{20} \cdot \omega_{10}^{2} \\
+\left(m_{3}+m_{3^{*}}+\frac{1}{2} \cdot m_{2^{*}}\right) \cdot d_{1} \cdot d_{2} \cdot \sin \phi_{20} \cdot \omega_{10}^{2} \\
+\frac{1}{2} \cdot m_{3^{*}} \cdot d_{2} \cdot d_{3} \cdot \sin \phi_{20} \cdot \cos \phi_{30} \cdot \omega_{10}^{2}
\end{array}\right.
$$

The total kinetic energy of the system and the third element are now partially derived, partly deriving the total kinetic energy of the system from the generalized coordinate $\omega_{30}$ (representing the angular velocity of the third actuator). The relationship is thus obtained (44):

$$
\left\{\begin{array}{l}
\frac{\partial \varepsilon}{\partial \omega_{30}}=\frac{1}{4} \cdot m_{3^{*}} \cdot \omega_{30} \cdot\left(d_{3}^{2}+r_{3^{*}}^{2}\right) \\
+\frac{1}{2} \cdot m_{3^{*}} \cdot d_{2} \cdot d_{3} \cdot \omega_{20} \cdot \cos \left(\phi_{30}-\phi_{20}\right) \\
+\frac{1}{2} \cdot m_{3^{*}} \cdot d_{3} \cdot\left(a_{2}+a_{3}\right) \cdot \sin \phi_{30} \cdot \omega_{10}
\end{array}\right.
$$

The absolute expression (44) obtained, considering the angular velocities of the actuators approximately constant over time, is obtained and the relation (45) is obtained:

$$
\begin{aligned}
& \frac{d}{d t}\left(\frac{\partial \varepsilon}{\partial \omega_{30}}\right)= \\
& =-\frac{1}{2} \cdot m_{3^{*}} \cdot d_{2} \cdot d_{3} \cdot \sin \left(\phi_{30}-\phi_{20}\right) \cdot\left(\omega_{30}-\omega_{20}\right) \cdot \omega_{20}+ \\
& +\frac{1}{2} \cdot m_{3^{*}} \cdot d_{3} \cdot\left(a_{2}+a_{3}\right) \cdot \cos \phi_{30} \cdot \omega_{30} \cdot \omega_{10}
\end{aligned}
$$

The kinetic energy of the entire system is partly derived from the angular displacement of the third actuator and the expression (46) results:

$$
\left\{\begin{array}{l}
\frac{\partial \varepsilon}{\partial \phi_{30}}=-\frac{1}{4} \cdot m_{3^{*}} \cdot d_{3}^{2} \cdot \cos \phi_{30} \cdot \sin \phi_{30} \cdot \omega_{10}^{2} \\
-\frac{1}{2} \cdot d_{1} \cdot d_{3} \cdot m_{3^{*}} \cdot \sin \phi_{30} \cdot \omega_{10}^{2} \\
-\frac{1}{2} \cdot m_{3^{*}} \cdot d_{2} \cdot d_{3} \cdot \cos \phi_{20} \cdot \sin \phi_{30} \cdot \omega_{10}^{2} \\
+\frac{1}{4} \cdot m_{3^{*}} \cdot r_{3^{*}}^{2} \cdot \sin \phi_{30} \cdot \cos \phi_{30} \cdot \omega_{10}^{2} \\
-\frac{1}{2} \cdot m_{3^{*}} \cdot d_{2} \cdot d_{3} \cdot \sin \left(\phi_{30}-\phi_{20}\right) \cdot \omega_{20} \cdot \omega_{30} \\
+\frac{1}{2} \cdot m_{3^{*}} \cdot d_{3} \cdot\left(a_{2}+a_{3}\right) \cdot \cos \phi_{30} \cdot \omega_{10} \cdot \omega_{30}
\end{array}\right.
$$

Using the relations (45) and (46) by introducing them into the Lagrange equation (47), the expression of the motor moment variation of the third actuator is obtained.

$\frac{d}{d t}\left(\frac{\partial \varepsilon}{\partial \omega_{30}}\right)-\frac{\partial \varepsilon}{\partial \phi_{30}}=M_{30}$

$\left\{\begin{array}{l}M_{30}=\frac{1}{2} \cdot m_{3^{*}} \cdot d_{2} \cdot d_{3} \cdot \sin \left(\phi_{30}-\phi_{20}\right) \cdot \omega_{20}^{2} \\ +\frac{1}{2} \cdot m_{3^{*}} \cdot d_{2} \cdot d_{3} \cdot \cos \phi_{20} \cdot \sin \phi_{30} \cdot \omega_{10}^{2} \\ +\frac{1}{4} \cdot m_{3^{*}} \cdot d_{3}^{2} \cdot \cos \phi_{30} \cdot \sin \phi_{30} \cdot \omega_{10}^{2} \\ -\frac{1}{4} \cdot m_{3^{*}} \cdot r_{3^{*}}^{2} \cdot \cos \phi_{30} \cdot \sin \phi_{30} \cdot \omega_{10}^{2} \\ +\frac{1}{2} \cdot m_{3^{*}} \cdot d_{1} \cdot d_{3} \cdot \sin \phi_{30} \cdot \omega_{10}^{2}\end{array}\right.$

\section{Discussion}

By using the expressions (38), (43) and (48), the variations of the motor moments, actuator moments, can be determined for the entire operating range. It uses the angular displacements and angles determined in the first courses, values given in the form of functions (in direct kinematics), obtained from the studied relations (in the indirect kinematics), or determined by the conditions imposed on the end-effector to go through certain optimized trajectories preset), (review course 5). A dynamic synthesis can be made to optimize the choice of the three actuators.

Interestingly, engine moments depend on the masses, shapes and dimensions of the elements, but also on kinematic actuator parameters: $\omega_{10}, \varphi_{20}, \varphi_{30}, \omega_{30} ; \varphi_{10}$ less.

So the motors are not dynamically influenced by the position of the first element, or more clearly, by the angle of rotation of the first element (Fig. 1), the dynamic movement being influenced only by the positions of the second and third elements and by the angular velocities of the three actuators.

\section{Conclusion}

The work presents an analytical method for determination of dynamic parameters in a $3 \mathrm{R}$ robotics module.

The dynamics of any system requires knowledge of the mechanical kinetic energy of the system. It is the starting point for the number one of determining dynamic calculations and relationships of any mechanical system. The problem with MP-3R systems is that they work spatially, so the kinetic energy of the system includes spatial elements (it can't fit only in a plan).

The Lagrange equation used has the known classical form (1). 


\section{Acknowledgement}

This text was acknowledged and appreciated by Dr. Veturia CHIROIU Honorific member of Technical Sciences Academy of Romania (ASTR) PhD supervisor in Mechanical Engineering.

\section{Funding Information}

Research contract: 1-Research contract: Contract number 36-5-4D/1986 from 24IV1985, beneficiary CNST RO (Romanian National Center for Science and Technology) Improving dynamic mechanisms.

2-Contract research integration. 19-91-3 from 29.03.1991; Beneficiary: MIS; TOPIC: Research on designing mechanisms with bars, cams and gears, with application in industrial robots.

3-Contract research. GR 69/10.05.2007: NURC in 2762; theme 8: Dynamic analysis of mechanisms and manipulators with bars and gears.

4-Labor contract, no. 35/22.01.2013, the UPB, "Stand for reading performance parameters of kinematics and dynamic mechanisms, using inductive and incremental encoders, to a Mitsubishi Mechatronic System" "PN-IIIN-CI-2012-1-0389".

All these matters are copyrighted! Copyrights: 394qodGnhhtej, from 17-02-2010 13:42:18; 463-vpstuCGsiy, from 20-03-2010 12:45:30; 631-sqfsgqvutm, from 24-052010 16:15:22; 933-CrDztEfqow, from 07-01-2011 13:37:52.

\section{Author's Contributions}

This section should state the contributions made by each author in the preparation, development and publication of this manuscript.

\section{Ethics}

Authors should address any ethical issues that may arise after the publication of this manuscript.

\section{References}

Antonescu, P. and F. Petrescu, 1985. An analytical method of synthesis of cam mechanism and flat stick. Proceedings of the 4th International Symposium on Mechanics Theory and Practice, (MTP' 85), Bucharest, July.

Antonescu, P. and F. Petrescu, 1989. Contributions to kinetoplast dynamic analysis of distribution mechanisms. SYROM'89, Bucharest, July.

Antonescu, P., M. Oprean and F. Petrescu, 1985a. Contributions to the synthesis of oscillating cam mechanism and oscillating flat stick. Proceedings of the 4th International Symposium on Theory and Practice of Mechanisms, (TPM' 85), Bucharest.
Antonescu, P., M. Oprean and F. Petrescu, 1985b. At the projection of the oscillate cams, there are mechanisms and distribution variables. Proceedings of the 5th Conference of Engines, Automobiles, Tractors and Agricultural Machines, Engines Automobiles, Brasov.

Antonescu, P., M. Oprean and F. Petrescu, 1986. Projection of the profile of the rotating camshaft acting on the oscillating plate with disengagement. Proceedings of the 3rd National Computer-Aided Design Symposium in the field of Mechanics and Machine Organs, (MMO' 86), Brasov.

Antonescu, P., M. Oprean and F. Petrescu, 1987. Dynamic analysis of the cam distribution mechanisms. Proceedings of the 7th National Symposium on Industrial Robots and Space Mechanisms, (RSM' 87), Bucharest.

Antonescu, P., M. Oprean and F. Petrescu, 1988 Analytical synthesis of Kurz profile, rotating the flat cam. Machine Building Magazine, Bucharest.

Antonescu, P., F. Petrescu and O. Antonescu, 1994. Contributions to the synthesis of the rotating cam mechanism and the tip of the balancing tip. PRASIC'94, Brasov.

Antonescu, P., F. Petrescu and D. Antonescu, 1997. Geometrical synthesis of the rotary cam and balance tappet mechanism. SYROM'97, 3: 23-23.

Antonescu, P., F. Petrescu and O. Antonescu, 2000a. Contributions to the synthesis of the rotary disc-cam profile. Proceedings of the 8th International Conference on the Theory of Machines and Mechanisms, (TMM' 00), Liberec, Czech Republic, pp: 51-56.

Antonescu, P., F. Petrescu and O. Antonescu, 2000b. Synthesis of the rotary cam profile with balance follower. Proceedings of the 8th Symposium on Mechanisms and Mechanical Transmissions, (MMT'00), Timişoara, pp: 39-44.

Antonescu, P., F. Petrescu and O. Antonescu, 2001. Contributions to the synthesis of mechanisms with rotary disc-cam. Proceedings of the 8th IFToMM International Symposium on Theory of Machines and Mechanisms, (TMM' 01), Bucharest, ROMANIA, pp: 31-36.

Aversa, R., R.V.V. Petrescu, A. Apicella and F.I.T. Petrescu, 2017a. Nano-diamond hybrid materials for structural biomedical application. Am. J. Biochem. Biotechnol.

Aversa, R., R.V. Petrescu, B. Akash, R.B. Bucinell and J.M. Corchado et al., 2017b. Kinematics and forces to a new model forging manipulator. Am. J. Applied Sci., 14: 60-80.

Aversa, R., R.V. Petrescu, A. Apicella, F.I.T. Petrescu and J.K. Calautit et al., 2017c. Something about the $\mathrm{V}$ engines design. Am. J. Applied Sci., 14: 34-52. 
Aversa, R., D. Parcesepe, R.V.V. Petrescu, F. Berto and G. Chen et al., 2017d. Processability of bulk metallic glasses. Am. J. Applied Sci., 14: 294-301.

Aversa, R., R.V.V. Petrescu, B. Akash, R.B. Bucinell and J.M. Corchado et al., 2017e. Something about the balancing of thermal motors. Am. J. Eng. Applied Sci.

Aversa, R., F.I.T. Petrescu, R.V. Petrescu and A. Apicella, 2016a. Biomimetic FEA bone modeling for customized hybrid biological prostheses development. Am. J. Applied Sci., 13: 1060-1067. DOI: 10.3844/ajassp.2016.1060.1067

Aversa, R., D. Parcesepe, R.V. Petrescu, G. Chen and F.I.T. Petrescu et al., 2016b. Glassy amorphous metal injection molded induced morphological defects. Am. J. Applied Sci., 13: 1476-1482.

Aversa, R., R.V. Petrescu, F.I.T. Petrescu and A. Apicella, 2016c. Smart-factory: Optimization and process control of composite centrifuged pipes. Am. J. Applied Sci., 13: 1330-1341.

Aversa, R., F. Tamburrino, R.V. Petrescu, F.I.T. Petrescu and M. Artur et al., 2016d. Biomechanically inspired shape memory effect machines driven by muscle like acting NiTi alloys. Am. J. Applied Sci., 13: 1264-1271.

Aversa, R., E.M. Buzea, R.V. Petrescu, A. Apicella and M. Neacsa et al., 2016e. Present a mechatronic system having able to determine the concentration of carotenoids. Am. J. Eng. Applied Sci., 9: 1106-1111.

Aversa, R., R.V. Petrescu, R. Sorrentino, F.I.T. Petrescu and A. Apicella, 2016f. Hybrid ceramo-polymeric nanocomposite for biomimetic scaffolds design and preparation. Am. J. Eng. Applied Sci., 9: 1096-1105.

Aversa, R., V. Perrotta, R.V. Petrescu, C. Misiano and F.I.T. Petrescu et al., 2016g. From structural colors to super-hydrophobicity and achromatic transparent protective coatings: Ion plating plasma assisted $\mathrm{TiO}_{2}$ and $\mathrm{SiO}_{2}$ Nano-film deposition. Am. J. Eng. Applied Sci., 9: 1037-1045.

Aversa, R., R.V. Petrescu, F.I.T. Petrescu and A. Apicella, 2016h. Biomimetic and evolutionary design driven innovation in sustainable products development. Am. J. Eng. Applied Sci., 9: 1027-1036.

Aversa, R., R.V. Petrescu, A. Apicella and F.I.T. Petrescu, 2016i. Mitochondria are naturally micro robots - a review. Am. J. Eng. Applied Sci., 9: 991-1002.

Aversa, R., R.V. Petrescu, A. Apicella and F.I.T. Petrescu, 2016j. We are addicted to vitamins $\mathrm{C}$ and E-A review. Am. J. Eng. Applied Sci., 9: 1003-1018.

Aversa, R., R.V. Petrescu, A. Apicella and F.I.T. Petrescu, 2016k. Physiologic human fluids and swelling behavior of hydrophilic biocompatible hybrid ceramo-polymeric materials. Am. J. Eng. Applied Sci., 9: 962-972.

Aversa, R., R.V. Petrescu, A. Apicella and F.I.T. Petrescu, 20161. One can slow down the aging through antioxidants. Am. J. Eng. Applied Sci., 9: 1112-1126.
Aversa, R., R.V. Petrescu, A. Apicella and F.I.T. Petrescu, $2016 \mathrm{~m}$. About homeopathy or $\ll$ Similia Similibus Curentur 》. Am. J. Eng. Applied Sci., 9: 1164-1172.

Aversa, R., R.V. Petrescu, A. Apicella and F.I.T. Petrescu, 2016n. The basic elements of life's. Am. J. Eng. Applied Sci., 9: 1189-1197.

Aversa, R., F.I.T. Petrescu, R.V. Petrescu and A. Apicella, 2016o. Flexible stem trabecular prostheses. Am. J. Eng. Applied Sci., 9: 1213-1221.

Berto, F., R.V.V. Petrescu and F.I.T. Petrescu, 2016a. A review of recent results on $3 \mathrm{D}$ effects. Am. J. Eng. Applied Sci., 9: 1247-1260.

Berto, F., R.V.V. Petrescu and F.I.T. Petrescu, 2016b. Three-dimensional in bonded joints: A short review. Am. J. Eng. Applied Sci., 9: 1261-1268.

Berto, F., A. Gagani, R.V.V. Petrescu and F.I.T. Petrescu, 2016c. Key-hole notches in isostatic graphite: A review of some recent data. Am. J. Eng. Applied Sci., 9: 1292-1300.

Berto, F., A. Gagani, R. Aversa, R.V.V. Petrescu and A. Apicella et al., 2016d. Multiaxial fatigue strength to notched specimens made of 40CrMoV13.9. Am. J. Eng. Applied Sci., 9: 1269-1291.

Cao, W., H. Ding, Z. Bin and C. Ziming, 2013. New structural representation and digital-analysis platform for symmetrical parallel mechanisms. Int. J. Advanced Robotic Sys., DOI: 10.5772/56380

Comanescu, A., 2010. Bazele Modelarii Mecanismelor. 1st Edn., E. Politeh Press, Bucureşti, pp: 274.

Dong, H., N. Giakoumidis, N. Figueroa and N. Mavridis, 2013. Approaching behaviour monitor and vibration indication in developing a General Moving Object Alarm System (GMOAS). Int. J. Adv. Robotic Sys. DOI: $10.5772 / 56586$

Franklin, D.J., 1930. Ingenious Mechanisms for Designers and Inventors. 1st Edn., Industrial Press, New York ISBN-10: 0831110325, pp: 486.

He, B., Z. Wang, Q. Li, H. Xie and R. Shen, 2013. An analytic method for the kinematics and dynamics of a multiple-backbone continuum robot. IJARS. DOI: $10.5772 / 54051$

Lee, B.J., 2013. Geometrical derivation of differential kinematics to calibrate model parameters of flexible manipulator. Int. J. Adv. Robotic Sys. DOI: $10.5772 / 55592$

Lin, W., B. Li, X. Yang and D. Zhang, 2013. Modelling and control of inverse dynamics for a 5-DOF parallel kinematic polishing machine. Int. J. Adv. Robotic Sys. DOI: 10.5772/54966

Liu, H., W. Zhou, X. Lai and S. Zhu, 2013. An efficient inverse kinematic algorithm for a PUMA560-structured robot manipulator. IJARS. DOI: $10.5772 / 56403$

Mirsayar, M.M., V.A. Joneidi, R.V.V. Petrescu, F.I.T. Petrescu and F. Berto, 2017. Extended MTSN criterion for fracture analysis of soda lime glass. Eng. Fracture Mechan., 178: 50-59. DOI: 10.1016/j.engfracmech.2017.04.018 
Padula, F. and V. Perdereau, 2013. An on-line path planner for industrial manipulators. Int. J. Adv. Robotic Sys. DOI: 10.5772/55063

Perumaal, S. and N. Jawahar, 2013. Automated trajectory planner of industrial robot for pick-andplace task. IJARS. DOI: 10.5772/53940

Petrescu, F. and R. Petrescu, 1995a. Contributions to optimization of the polynomial motion laws of the stick from the internal combustion engine distribution mechanism. ESFA, 1: 249-256.

Petrescu, F. and R. Petrescu, 1995b. Contributions to the synthesis of internal combustion engine distribution mechanisms. ESFA, Bucharest, 1: 257-264.

Petrescu, F. and R. Petrescu, 1997a. Dynamics of cam mechanisms (exemplified on the classic distribution mechanism). SYROM'97, Bucharest, 3: 353-358.

Petrescu, F. and R. Petrescu, 1997b. Contributions to the synthesis of the distribution mechanisms of internal combustion engines with a Cartesian coordinate method. SYROM'97, Bucharest, 3: 359-364.

Petrescu, F. and R. Petrescu, 1997c. Contributions to maximizing polynomial laws for the active stroke of the distribution mechanism from internal combustion engines. SYROM'97, Bucharest, 3: 365-370.

Petrescu, F. and R. Petrescu, 2000a. Synthesis of distribution mechanisms by the rectangular (Cartesian) coordinate method. Proceedings of the Grafica Conference, University of Craiova, (CUC' 00), Craiova.

Petrescu, F. and R. Petrescu, 2000b. The design (synthesis) of cams using the polar coordinate method (the triangle method). Proceedings of the Grafica Conference, University of Craiova, (CUC' 00), Craiova.

Petrescu, F. and R. Petrescu, 2002a. Motion laws for camshafts. Proceedings of the 8th Lea National Symposium on International Computer Assisted Design (PAC' 02), Braşov, pp: 321-326.

Petrescu, F. and R. Petrescu, 2002b. Camshaft dynamics elements. Proceeding of the VIIth National Symposium on International Participation Computer Assisted Design (PAC' 02), Braşov, pp: 327-332.

Petrescu, F. and R. Petrescu, 2003. Some elements regarding the improvement of the engine design. Proceedings of the 8th National Symposium, Descriptive Geometry, Technical Graphics and Design, (GTD’ 03), Braşov, pp: 353-358.

Petrescu, F. and R. Petrescu, 2005a. The cam design for a better efficiency. Proceedings of the International Conference on Engineering Graphics and Design, (EGD' 05), Bucharest, pp: 245-248.

Petrescu, F. and R. Petrescu, 2005b. Contributions at the dynamics of cams. Proceedings of the 9th IFToMM International Symposium on Theory of Machines and Mechanisms, (TMM' 05), Bucharest, Romania, pp: 123-128.
Petrescu, F. and R. Petrescu, 2005c. Determining the dynamic efficiency of cams. Proceedings of the 9th IFToMM International Symposium on Theory of Machines and Mechanisms, (TMM' 05), Bucharest, Romania, pp: 129-134.

Petrescu, F. and R. Petrescu, 2005d. An original internal combustion engine. Proceedings of the 9th IFToMM International Symposium on Theory of Machines and Mechanisms, (TMM' 05), Bucharest, Romania, pp: 135-140.

Petrescu, F. and R. Petrescu, 2005e. Determining the mechanical efficiency of Otto engine's mechanism. Proceedings of the 9th IFToMM International Symposium on Theory of Machines and Mechanisms, (TMM' 05), Bucharest, Romania, pp: 141-146.

Petrescu, F.I. and R.V. Petrescu, 2011. Mechanical Systems, Serial and Parallel. 1st Edn., LULU Publisher, London, UK, pp: 124.

Petrescu, F.I. and R.V. Petrescu, 2012a. Kinematics of the planar quadrilateral mechanism. Engevista, 14: 345-348.

Petrescu, F.I. and R.V. Petrescu, 2012b Mecatronicasisteme seriale si paralele. 1st Edn., Create Space Publisher, USA, pp: 128.

Petrescu, F.I. and R.V. Petrescu, 2013a. Cinematics of the 3R dyad. Engevista, 15: 118-124.

Petrescu, F.I., Petrescu, R.V., 2013b Forces and efficiency of cams. Int. Rev. Mechanical Eng.

Petrescu, F.I. and R.V. Petrescu, 2016a. Parallel moving mechanical systems kinematics. ENGEVISTA, 18: 455-491.

Petrescu, F.I. and R.V. Petrescu, 2016b. Direct and inverse kinematics to the anthropomorphic robots. ENGEVISTA, 18: 109-124.

Petrescu, R.V., R. Aversa, B. Akash, R. Bucinell and J. Corchado et al., 2017a. Yield at thermal engines internal combustion. Am J. Eng. Applied Sci., 10: 243-251.

Petrescu, R.V., R. Aversa, B. Akash, B. Ronald and J. Corchado et al., 2017b. Velocities and accelerations at the $3 \mathrm{R}$ mechatronic systems. Am. J. Eng. Applied Sci., 10: 252-263.

Petrescu, R.V., R. Aversa, B. Akash, R. Bucinell and J. Corchado et al., 2017c. Anthropomorphic solid structures n-R kinematics. Am. J. Eng. Applied Sci., 10: 279-291.

Petrescu, R.V., R. Aversa, B. Akash, R. Bucinell and J. Corchado et al., 2017d. Inverse kinematics at the anthropomorphic robots, by a trigonometric method. Am. J. Eng. Applied Sci., 10: 394-411.

Petrescu, R.V., R. Aversa, B. Akash, R. Bucinell and J. Corchado et al., 2017e. Forces at internal combustion engines. Am. J. Eng. Applied Sci., 10: 382-393.

Petrescu, R.V., R. Aversa, B. Akash, R. Bucinell and J. Corchado et al., 2017f. Gears-part I. Am. J. Eng. Applied Sci., 10: 457-472. 
Petrescu, RV., R. Aversa, B. Akash, R. Bucinell and J. Corchado et al., 2017g. Gears-part II. Am. J. Eng. Applied Sci., 10: 473-483.

Petrescu, R.V., R. Aversa, B. Akash, R. Bucinell and J. Corchado et al., 2017h. Cam-gears forces, velocities, powers and efficiency. Am. J. Eng. Applied Sci., 10: 491-505.

Petrescu, R.V., R. Aversa, B. Akash, R. Bucinell and J. Corchado et al., 2017i. Dynamics of mechanisms with cams illustrated in the classical distribution. Am. J. Eng. Applied Sci., 10: 551-567.

Petrescu, R.V., R. Aversa, B. Akash, R. Bucinell and J. Corchado et al., 2017j. Testing by non-destructive control. Am. J. Eng. Applied Sci., 10: 568-583.

Petrescu, R.V., R. Aversa, A. Apicella and F.I.T. Petrescu, 2017k. Transportation engineering. Am. J. Eng. Applied Sci., 10: 685-702.

Petrescu, R.V., R. Aversa, S. Kozaitis, A. Apicella and F.I.T. Petrescu, 20171. The quality of transport and environmental protection, part i. Am. J. Eng. Applied Sci., 10: 738-755.
Petrescu, F.I. and R.V. Petrescu, 2016c. Dynamic cinematic to a structure 2R. Revista Geintec-Gestao Inovacao E Tecnologias, 6: 3143-3154.

Petrescu, R.V., R. Aversa, A. Apicella and F.I. Petrescu, 2016. Future medicine services robotics. Am. J. Eng. Applied Sci., 9: 1062-1087.

Petrescu, F.I., B. Grecu, A. Comanescu and R.V. Petrescu, 2009. Some mechanical design elements. Proceeding of the International Conference on Computational Mechanics and Virtual Engineering, (COMEC' 2009), Braşov, pp: 520-525.

Petrescu, F.I., Teoria Mecanismelor si a Masinilor. 1st Edn., Create Space Publisher, USA, pp: 432.

Petrescu, F.I.T., 2015a. Geometrical synthesis of the distribution mechanisms. Am. J. Eng. Applied Sci., 8: 63-81.

Petrescu, F.I.T., 2015b. Machine motion equations at the internal combustion heat engines. Am. J. Eng. Applied Sci., 8: 127-137. 